\title{
Effect of oven and freeze drying on antioxidant activity, total phenolic and total flavonoid contents of fig (Ficus carica L.) leaves
}

\author{
${ }^{1}$ Elshaafi, I.M., ${ }^{2}$ Musa, K.H. and ${ }^{3, *}$ Abdullah Sani, N. \\ ${ }^{1}$ Department of Biological Sciences and Biotechnology, Faculty of Science and Technology, Universiti \\ Kebangsaan Malaysia, 43600, UKM Bangi, Selangor, Malaysia \\ ${ }^{2}$ Faculty of Agriculture and Veterinary Medicine, Qassim University, Buraydah, Qassim, Saudi Arabia \\ ${ }^{3}$ Department of Food Sciences, Faculty of Science and Technology, Universiti Kebangsaan Malaysia, \\ 43600, UKM Bangi, Selangor, Malaysia
}

\section{Article history:}

Received: 17 February 2020

Received in revised form: 12

April 2020

Accepted: 14 April 2020

Available Online: 8

September 2020

Keywords:

Ficus carica L.,

Drying,

Antioxidant,

Total phenolic,

Total flavonoid

DOI:

https://doi.org/10.26656/fr.2017.4(6).072

\begin{abstract}
Effect of drying processes on the antioxidant activities, total phenolic (TPC) and total flavonoid (TFC) contents of three fig (Ficus carica L.) leaves' cultivars namely Brown Turkey Masuri 6 (BTM 6), Masui Dauphine Jumbo (MD-J) and Taiwan Golden Fish Jumbo (TGF-J) were studied. Oven drying which was conducted at $40^{\circ} \mathrm{C}, 50^{\circ} \mathrm{C}, 60^{\circ} \mathrm{C}$ and freeze drying at $-80^{\circ} \mathrm{C}$ were run for $48 \mathrm{hrs}$. Antioxidant activities were evaluated using radical-scavenging capacity by 2,2-diphenyl-1-picrylhydrazyl (DPPH), 2,2'-azino-bis (3ethylbenzothiazoline-6-sulphonic acid) (ABTS), ferric-reducing antioxidant power (FRAP) and cupric reducing antioxidant capacity (CUPRAC) assays. TPC and TFC were evaluated using Folin-Ciocaltue and aluminum chloride assays respectively. It was found that using oven drying at $40^{\circ} \mathrm{C}$ revealed significantly $(\mathrm{p}<0.05)$ the highest antioxidant activities of the three fig cultivars followed by oven drying at $50^{\circ} \mathrm{C}$, freeze dried and oven drying at $60^{\circ} \mathrm{C}$ respectively. Fresh leaves revealed the significantly lowest antioxidant activities for all antioxidant assays and for all fig cultivars. Regardless of the drying process, fig cultivar BTM 6 revealed significantly $(\mathrm{p}<0.05)$ the highest antioxidant activities followed by TGF-J and MD-J. Positive correlations between antioxidant, TPC and TFC activities of fig leaves extracts were observed at oven drying at $40^{\circ} \mathrm{C}$, oven drying at $60^{\circ} \mathrm{C}$ and freeze drying but not with oven drying at $50^{\circ} \mathrm{C}$ and fresh samples. High levels of antioxidant activities were obtained in $F$. carica L. leave samples (all cultivars), indicating that the leaves have potential as a source of natural antioxidants compounds.
\end{abstract}

\section{Introduction}

In the past few years, farmers in Malaysia successfully started importing and growing different fig (Ficus carica L.) cultivars, where the main products sold are fruits and leaves. Their leaves have been used as a tea and claimed to have medicinal properties. Previous studies of antioxidant activity of fig leaves were conducted (Trifunschi and Ardelean, 2013; Ahmad et al., 2013; Allahyari et al., 2014), but no research has been directed on the impact of drying process on their antioxidant, total phenolic (TPC) and total flavonoid (TFC) activities.

The benefits of fig leaves are associated with the secondary metabolites made by these plants. The use of plants as an origin of antioxidants remains substantial for the reason that they are consumed to heal illnesses (Oliveira et al., 2006; Lim and Murtijaya, 2007; Hossain et al., 2010). Moreover, the secondary metabolites of plant work as antioxidants have been proved to fight cardiovascular diseases, cancer and diabetes (Chan et al., 2009; Shahinuzzaman et al., 2019). The protective properties fighting these illnesses remain possibly implemented by the occurrence of several functional secondary metabolites, like polyphenols, vitamins and minerals (Asami et al. 2003; Chang et al., 2006; Roy et al., 2007; Sagrin and Chong, 2013). Polyphenols from various plant sources include an excessive diversity of bioactive compounds, such as flavonoids (anthocyanins, flavonols, flavanols, flavanones) and numerous classes of non-flavonoids such as (phenolic acids, stilbenes and other molecules) (Panche et al., 2016; Tan et al., 2018). 
Drying is mainly a process of water removing and reducing the content of moisture, intended to prevent enzymatic and microbial activities, subsequently protecting the crop for lengthening shelf life and phytochemical effectiveness. Furthermore, it also reduces the volume and weight of the crop with significant positive consequences to improve reduction of final product cost, such as storage and shipping (Calixto, 2000; Chan et al., 2009; Tan et al., 2013).

Nevertheless, to the best of our knowledge, there is no literature on the effect of drying of Ficus carica L. leaves on the antioxidant, TPC and TFC. Among the most used drying technique is oven drying which is easy to handle, available and relatively cheap to operate. While freeze drying is not as reachable as oven drying, it is assumed to be more efficient medicinally to other drying methods.

Since antioxidants are delicate to air, heat and light, an appropriate drying process procedure must be optimized for each type of plant's leaves depending on their structure physically and chemically. Therefore, the aim of this study was to evaluate the effectiveness of oven and freeze-drying processes on the TPC, TFC and antioxidant activities of selected fig leaves cultivars.

\section{Materials and methods}

\subsection{Samples collection and preparation}

Fig ( $F$. carica L.) leave samples were freshly collected from a fig farm (Taman Agro-Fertigasi) located in Kajang, Malaysia. There were three F. carica L. leaves' cultivars namely Brown Turkey Masuri 6 (BTM 6), Masui Dauphine Jumbo (MD-J) and Taiwan Golden Fish Jumbo (TGF-J). The leaves' samples were transported back to the food science laboratory in the Faculty of Science and Technology, Universiti Kebangsaan Malaysia. to be processed accordingly. The samples were divided to two groups; the first as fresh and the second were handled with two drying methods: non-thermal drying using a freeze dryer (Labconco, Benchtop Freeze Dry, USA) and thermal drying using an oven at different temperatures $\left(40^{\circ} \mathrm{C}, 50^{\circ} \mathrm{C}\right.$ and $\left.60^{\circ} \mathrm{C}\right)$ (Memmert Gmbh + CO. KG, Germany) for 48 hrs, then ground with a food grinder (Philips, China) to produce a fine powder. About $0.1 \mathrm{~g}$ each of $F$. carica L. leave samples were weighed and $10 \mathrm{~mL}$ aqueous $50 \%$ acetone (VWR International, France) was added. All extracted samples were centrifuged using Eppendorf centrifuge (5810 R, Eppendorf, Germany) for 10 mins at $2180 \times g$ and then filtered with $0.22 \mu \mathrm{m}$ PTFE syringe filter (Osaka Chemical, China).

\subsection{Determination of moisture content}

Moisture content was determined after $48 \mathrm{hrs}$ of oven drying by Association of Official Analytical Chemists (AOAC) (Association of Social Analytical Chemist, 1990) methods.

\subsection{Determination of total phenolic content (TPC)}

The determination of TPC was conducted based on Singleton and Rossi (1965) with modification based on the method of Aminah and Permatasari (2013). The calculation of results was based on the equation generated by the gallic acid standard curve. The result was expressed as milligrams of gallic acid equivalents per $100 \mathrm{~g}$ of dry sample (mg GAE/100 g DW).

\subsection{Determination of total flavonoid content (TFC)}

TFC content was determined following the method of Benzie and Strain (1996) with modification based on the method of Bakar et al. (2009). The calculation of results was based on the equation generated by quercetin standard curve. Results were expressed as milligrams of quercetin equivalents $(\mathrm{QE})$ per $100 \mathrm{~g}$ of dry sample (mg $\mathrm{QE} / 100 \mathrm{~g} \mathrm{DW})$.

\subsection{Antioxidant assay determination}

\subsubsection{Radical-scavenging activity (DPPH)}

DPPH determination was carried out according to the method of Musa et al. (2011). The calculation of results was based on the equation generated by Trolox standard curve. Results were expressed as milligrams of Trolox equivalents per $100 \mathrm{~g}$ of dry sample (mg TE/100 g DW).

\subsubsection{Radical-scavenging activity (ABTS)}

ABTS determination was carried out according to the method of van den Berg et al. (1999). The calculation of results was based on the equation generated by Trolox standard curve. Results were expressed as milligrams of Trolox equivalents per $100 \mathrm{~g}$ of dry sample (mg TE/100 g DW).

\subsubsection{Ferric reducing/ antioxidant power (FRAP)}

FRAP determination was carried out according to the method of Benzie and Strain (1999) with modification based on the method of Abdullah Sani et al. (2018). The calculation of results was based on the equation generated by Trolox standard curve. Results were expressed as milligrams of Trolox equivalents per $100 \mathrm{~g}$ of dry sample (mg TE/100 g DW). 


\subsubsection{Cupric reducing antioxidant capacity (CUPRAC)}

CUPRAC determination was carried out according to the method of Apak et al. (2008). The calculation of results was based on the equation generated by Trolox standard curve. Results were expressed as milligrams of Trolox equivalents per $100 \mathrm{~g}$ of dry sample (mg TE/100 g DW).

\subsection{Statistical analysis}

Data were analyzed using MINITAB $\AA$ (version 17.1.0, USA). One-way ANOVA with Fisher test at $\mathrm{p}<0.05$ was carried out to test significant differences between levels of treatment. Principal component analysis (PCA) was performed using XLstate software (Addinsoft, version 2016.02, France). Pearson's correlation analyses were performed to determine the relationship between antioxidant, TPC and TFC activities.

\section{Results}

\subsection{Moisture content}

The moisture content of fig leaves was determined after drying processes were completed. No significant difference $(p<0.05)$ in the moisture content was shown between the three fig cultivars and the values were $81.63 \%, 82.35 \%, 83.57 \%$ and for fig cultivars MD-J, BTM 6 and TGF-J respectively as in Table 1.

\subsection{Effect of drying on the total phenolic content (TPC)}

The TPC of the three fig leaves' cultivars were affected by drying processes. As in Table 1, oven drying at $40^{\circ} \mathrm{C}$ showed the highest TPC for the three cultivars, where BTM 6 revealed significantly $(p<0.05)$ the highest activity (1,125 mg GAE/100 g DW), followed by TGF-J (1,056 $\mathrm{mg}$ GAE/100 $\mathrm{g}$ DW) and MD-J (993 mg GAE/100 g DW). Significantly there were no differences among freeze drying and oven drying at $\left(50^{\circ} \mathrm{C}\right.$ and $\left.60^{\circ} \mathrm{C}\right)$ results of the three fig cultivars, where the activities were ranging from 591 to $655 \mathrm{mg}$ GAE/100 $\mathrm{g} \mathrm{DW}$. In contrast, fresh leaves showed significantly $(p<0.05)$ the lowest TPC and ranged between 187 to $240 \mathrm{mg}$ GAE/100 g DW.

\subsection{Effect of drying on the total flavonoid content (TFC)}

The TFC of the three fig leaves' cultivars were affected by drying process. As in Table 1, fig cultivar BTM 6 showed significantly $(\mathrm{p}<0.05)$ the highest activity $(8,277 \mathrm{mg}$ QE/100 $\mathrm{g}$ DW) with oven drying at $40^{\circ} \mathrm{C}$, followed by fig cultivars TGF-J (7,055 mg QE/100 $\mathrm{g}$ DW). There were no significant differences between oven drying of fig cultivar MD-J (4,888 mg QE/100 g DW) at $40^{\circ} \mathrm{C}$ and oven drying of fig cultivar BTM 6 $(4,500 \mathrm{mg} \mathrm{QE} / 100 \mathrm{~g} \mathrm{DW})$ at $50^{\circ} \mathrm{C}$. There were no significant differences between freeze drying of fig cultivar BTM 6 (3,389 $\mathrm{mg}$ QE/100 g DW) and oven drying of fig cultivar TGF-J $(4,888 \mathrm{mg} \mathrm{QE} / 100 \mathrm{~g} \mathrm{DW})$ at $50^{\circ} \mathrm{C}$. There were no significant differences between

Table 1. Effect of drying process on the antioxidant activity of fig leaves by total phenolic content (TPC) ${ }^{\mathrm{A}}$, total flavonoid content $(\mathrm{TFC})^{\mathrm{B}}$, radical-scavenging activity $(\mathrm{DPPH})^{\mathrm{C}}, \mathrm{ABTS}^{\mathrm{D}}$, ferric-reducing antioxidant power $(\mathrm{FRAP})^{\mathrm{E}}$, cupric reducing antioxidant capacity (CUPRAC) ${ }^{\mathrm{F}}$

\begin{tabular}{|c|c|c|c|c|c|c|c|c|}
\hline Fig cultivar & $\begin{array}{l}\text { Drying } \\
\text { process }\end{array}$ & $\begin{array}{l}\text { Moisture } \\
\text { content }\end{array}$ & TPC & TFC & DPPH & ABTS & FRAP & CUPRAC \\
\hline \multirow{5}{*}{ BTM 6} & $40^{\circ} \mathrm{C}$ & \multirow{5}{*}{$82.35 \%$} & $1,125 \pm 95^{\mathrm{a}}$ & $8,277 \pm 385^{a}$ & $1,740 \pm 68^{\mathrm{a}}$ & $2,917 \pm 108^{a}$ & $2,015 \pm 36^{\mathrm{a}}$ & $3,893 \pm 162^{\mathrm{a}}$ \\
\hline & $50^{\circ} \mathrm{C}$ & & $645 \pm 35^{\text {def }}$ & $4,500 \pm 289^{c}$ & $581 \pm 36^{\mathrm{f}}$ & $1,848 \pm 127^{\mathrm{c}}$ & $943 \pm 22^{d}$ & $1,984 \pm 49^{d}$ \\
\hline & $60^{\circ} \mathrm{C}$ & & $655 \pm 27^{\mathrm{de}}$ & $3,166 \pm 289^{\mathrm{de}}$ & $651 \pm 89^{e}$ & $1,865 \pm 288^{\mathrm{c}}$ & $708 \pm 28^{\mathrm{e}}$ & $1,800 \pm 62^{\mathrm{e}}$ \\
\hline & Freeze dried & & $655 \pm 12^{\mathrm{de}}$ & $3,389 \pm 347^{\mathrm{d}}$ & $704 \pm 38^{\mathrm{de}}$ & $1,737 \pm 8^{\mathrm{cd}}$ & $959 \pm 32^{d}$ & $1,954 \pm 24^{\mathrm{d}}$ \\
\hline & Fresh & & $187 \pm 14^{\mathrm{g}}$ & $1,388 \pm 96^{\mathrm{g}}$ & $168 \pm 32^{\mathrm{i}}$ & $526 \pm 134^{\mathrm{f}}$ & $134 \pm 15^{\mathrm{i}}$ & $434 \pm 18^{i}$ \\
\hline \multirow{5}{*}{ MD-J } & $40^{\circ} \mathrm{C}$ & \multirow{5}{*}{$81.63 \%$} & $993 \pm 33^{c}$ & $4,888 \pm 255^{\mathrm{c}}$ & $1,479 \pm 49^{\mathrm{c}}$ & $2,292 \pm 187^{b}$ & $1,661 \pm 26^{\mathrm{c}}$ & $3,011 \pm 176^{\mathrm{c}}$ \\
\hline & $50^{\circ} \mathrm{C}$ & & $666 \pm 24^{\mathrm{d}}$ & $2,889 \pm 255^{\mathrm{ef}}$ & $674 \pm 36^{\mathrm{de}}$ & $1,523 \pm 220^{\mathrm{de}}$ & $647 \pm 31^{\mathrm{fg}}$ & $1,738 \pm 61^{\mathrm{e}}$ \\
\hline & $60^{\circ} \mathrm{C}$ & & $605 \pm 22^{\mathrm{ef}}$ & $1,555 \pm 192^{\mathrm{g}}$ & $502 \pm 41^{\mathrm{g}}$ & $1,548 \pm 105^{\mathrm{de}}$ & $622 \pm 4^{\mathrm{g}}$ & $1,417 \pm 68^{\mathrm{g}}$ \\
\hline & Freeze dried & & $625 \pm 15^{\text {def }}$ & $2,889 \pm 254^{\mathrm{ef}}$ & $663 \pm 28^{\mathrm{de}}$ & $1,703 \pm 121^{\mathrm{cd}}$ & $693 \pm 23^{e}$ & $1,724 \pm 47^{\mathrm{e}}$ \\
\hline & Fresh & & $216 \pm 28^{g}$ & $1,222 \pm 152^{\mathrm{g}}$ & $298 \pm 12^{\mathrm{h}}$ & $606 \pm 265^{f}$ & $241 \pm 21^{\mathrm{h}}$ & $634 \pm 16^{\mathrm{h}}$ \\
\hline \multirow{5}{*}{ TGF-J } & $40^{\circ} \mathrm{C}$ & \multirow{5}{*}{$83.57 \%$} & $1,056 \pm 24^{b}$ & $7,055 \pm 536^{\mathrm{b}}$ & $1,640 \pm 15^{b}$ & $2,362 \pm 237^{b}$ & $1,746 \pm 32^{b}$ & $3,473 \pm 61^{b}$ \\
\hline & $50^{\circ} \mathrm{C}$ & & $613 \pm 22^{\text {def }}$ & $3,389 \pm 245^{\mathrm{d}}$ & $729 \pm 28^{d}$ & $1,484 \pm 91^{\mathrm{de}}$ & $632 \pm 9^{\mathrm{g}}$ & $1,552 \pm 45^{\mathrm{fg}}$ \\
\hline & $60^{\circ} \mathrm{C}$ & & $626 \pm 41^{\text {def }}$ & $1,666 \pm 167^{\mathrm{g}}$ & $681 \pm 17^{\mathrm{de}}$ & $1,537 \pm 146^{\mathrm{de}}$ & $699 \pm 18^{\mathrm{e}}$ & $1,782 \pm 145^{\mathrm{e}}$ \\
\hline & Freeze dried & & $591 \pm 44^{\mathrm{f}}$ & $2,610 \pm 96^{\mathrm{f}}$ & $703 \pm 22^{\text {de }}$ & $1,387 \pm 101^{\mathrm{e}}$ & $685 \pm 10^{\mathrm{ef}}$ & $1,681 \pm 6^{\mathrm{ef}}$ \\
\hline & Fresh & & $240 \pm 22^{\mathrm{g}}$ & $444 \pm 36^{\mathrm{h}}$ & $303 \pm 17^{\mathrm{h}}$ & $509 \pm 133^{\mathrm{f}}$ & $272 \pm 4^{\mathrm{h}}$ & $523 \pm 12^{\mathrm{hi}}$ \\
\hline
\end{tabular}

Results showed mean \pm SD in triplicate. ${ }^{\text {a-i }}$ Values in each column marked by the same letter are not significantly different at $\mathrm{p}>0.05$. ${ }^{\mathrm{A}}$ Milligrams of gallic acid equivalent (GAE) per $100 \mathrm{~g}$ of dry weight (DW). ${ }^{\mathrm{B}}$ Milligrams of quercetin equivalent (QE) per $100 \mathrm{~g}$ of dry weight (DW). ${ }^{\text {C,D,E,F }}$ Milligrams of Trolox equivalent (TE) per $100 \mathrm{~g}$ dry weight (DW) 
oven drying at $60^{\circ} \mathrm{C}$ and fresh leaves' samples.

\subsection{Effect of drying on the antioxidant activities}

3.4.1 Effect of drying on radical-scavenging activity (DPPH)

The radical-scavenging activity by DPPH assay of three fig leaves' cultivars was affected by drying processes (Table 1). The oven drying at $40^{\circ} \mathrm{C}$ showing the highest activity were fig cultivar BTM 6 revealing significantly $(\mathrm{p}<0.05)$ the highest activity $(1,740 \mathrm{mg}$ TE/100 g DW), followed by fig cultivars TGF-J (1,641 $\mathrm{mg}$ TE/100 g DW) and MD-J (1,479 mg TE/100 g DW) respectively. There were no significant $(p<0.05)$ differences between freeze drying for all the three cultivars tested. Fresh samples revealed significantly $(\mathrm{p}<0.05)$ the lowest activity and ranged between 303 to $168 \mathrm{mg}$ TE/100 g DW.

\subsubsection{Effect of drying on radical-scavenging activity (ABTS)}

The radical-scavenging activity by ABTS assay of three fig leaves' cultivars was affected by the drying process (Table 1). Oven drying at $40^{\circ} \mathrm{C}$ revealed the highest antioxidant activity was fig cultivar BTM 6 revealed significantly $(p<0.05)$ the highest antioxidant activity $(2,917 \mathrm{mg}$ TE/100 $\mathrm{g}$ DW) followed by fig cultivars TGF Jumbo (2,362 mg TE/100 g DW) and MD Jumbo (2,293 mg TE/100 g DW).

\subsubsection{Effect of drying on ferric reducing/ antioxidant power (FRAP)}

The antioxidant activity by FRAP assay of the three fig leaves' cultivars was affected by drying process (Table 1). Fig cultivar BTM 6 showed significantly $(p<0.05)$ the highest activity $(2,014 \mathrm{mg} / 100 \mathrm{~g}$ DW $)$ followed by fig cultivars TGF-J (1,746 mg TE/100 g DW) and MD-J (1,661 mg TE/100 g DW) respectively. Fig cultivar BTM 6 showed no significant difference between freeze drying (959 mg TE/100 g DW) and oven drying at $50^{\circ} \mathrm{C}(943 \mathrm{mg} \mathrm{TE} / 100 \mathrm{~g} \mathrm{DW})$. There were no significant differences between oven drying at $60^{\circ} \mathrm{C}$ for both fig cultivars BTM 6 (708 mg TE/100 g DW) and TGF-J (699 mg TE/100 g DW) and freeze drying for both fig cultivars MD-J (693 mg TE/100 g DW) and TGF-J (685 mg TE/100 g DW). Fresh fig leaves for the three fig cultivars showed less significant difference.

\subsubsection{Effect of drying on cupric reducing antioxidant capacity (CUPRAC)}

The antioxidant activity by CUPRAC assay of the three fig leaves' cultivars was affected by drying processes (Table 1). At $40^{\circ} \mathrm{C}$ fig cultivar BTM 6 showed significantly $(\mathrm{p}<0.05)$ the highest activity $(3,893 \mathrm{mg}$
TE/100 g DW), followed by fig cultivars TGF-J $(3,473$ $\mathrm{mg}$ TE/100 g DW) and MD-J (3,011 mg TE/100 g DW) respectively. Fig cultivar BTM 6 revealed no significant differences between freeze drying $(1,984 \mathrm{mg}$ TE/100 $\mathrm{g}$ DW) and oven drying at $50^{\circ} \mathrm{C}(1,954 \mathrm{mg} \mathrm{TE} / 100 \mathrm{~g} \mathrm{DW})$. There were no significant differences between oven drying at $60^{\circ} \mathrm{C}$ for both the fig leaves' cultivars BTM 6 (1,800 mg TE/100 g DW) and TGF-J (1,782 mg TE/100 $\mathrm{g} \mathrm{DW})$, oven drying for fig cultivar MD-J at $50^{\circ} \mathrm{C}(1,738$ $\mathrm{mg}$ TE/100 g DW) and freeze drying for both fig leaves' cultivars MD-J (1,724 mg TE/100 g DW) and TGF-J (1,681 mg TE/100 g DW).

\subsection{Correlation analysis}

The correlations between antioxidant, TPC and TFC activities with regard to the different drying processes were studied (Table 2). Drying fig leaves at $40^{\circ} \mathrm{C}$ showed high positive correlation between all antioxidant, TPC and TFC assays. DPPH and TFC (1.000) revealed significantly $(\mathrm{p}<0.05)$ the highest correlation followed by CUPRAC with TPC (0.999). ABTS with TFC (0.836) revealed the least positive correlation. While drying fig leaves at $50^{\circ} \mathrm{C}$ revealed a mix of correlations ranging from high negative to high positive correlation. TPC and TFC revealed low negative correlation $(-0.187)$, while DPPH and TPC (-0.480) revealed a medium negative correlation. On the other hand, ABTS, FRAP and CUPRAC with TPC showed low to medium positive correlation ranging from 0.215 to 0.533 respectively. ABTS and FRAP with TFC showed high positive correlation (0.919 and 0.939) respectively. DPPH revealed a strong negative correlation with ABTS, FRAP and CUPRAC ranging from -0.960 to -0.998 respectively. The highest positive correlation $(\mathrm{p}<0.05)$ were between ABTS and FRAP assays (0.998). Drying fig leaves at $60^{\circ} \mathrm{C}$ revealed medium to high positive correlations between TPC, TFC and antioxidant activities in contrary with drying at $50^{\circ} \mathrm{C}$, and the FRAP with CUPRAC assays showed significantly $(p<0.05)$ the highest positive correlation (0.999). Drying fig leaves with a freeze dryer showed a mixture of correlations ranging from medium, negative to high positive correlation. TPC with TFC, ABTS, CUPRAC and FRAP revealed high positive correlation ranging from 0.979 to 0.859 . While TPC and DPPH (-0.012) revealed a low negative correlation. TFC and DPPH (0.190) revealed low positive correlation while TFC with ABTS, FRAP and CUPRAC revealed high positive correlation ranging from 0.825 to 0.977 . DPPH and ABTS $(-0.398)$ revealed a medium negative correlation while DPPH with FRAP and CUPRAC showed medium positive correlation at 0.502 and 0.395 respectively. The highest correlation with freeze drying was showed between FRAP and CUPRAC assays at 0.993. TPC, TFC and antioxidant 
Table 2. Pearson's correlation coefficients between TPC, TFC and antioxidant activities ${ }^{\mathrm{x}}$ under influence of different drying process $(\mathrm{n}=3)^{\cdot \mathrm{y}}$

\begin{tabular}{ccccccc}
\hline Drying process & Correlation coefficient $(r)$ & TPC & TFC & DPPH & ABTS & FRAP \\
\hline \multirow{5}{*}{$40^{\circ} \mathrm{C}$} & TFC & 0.983 & & & & \\
& DPPH & 0.987 & $1.000^{*}$ & & & \\
& ABTS & 0.922 & 0.836 & 0.848 & & \\
& FRAP & 0.965 & 0.901 & 0.911 & 0.991 & \\
5 & CUPRAC & $0.999^{*}$ & 0.991 & 0.994 & 0.901 & 0.95 \\
$50^{\circ} \mathrm{C}$ & TFC & -0.187 & & & & \\
& DPPH & -0.48 & -0.772 & & & \\
& ABTS & 0.215 & 0.919 & -0.96 & & \\
& FRAP & 0.161 & 0.939 & -0.943 & $0.998^{*}$ & \\
& CUPRAC & 0.533 & 0.731 & $-0.998^{*}$ & 0.941 & 0.921 \\
\hline \multirow{5}{*}{$60^{\circ} \mathrm{C}$} & TFC & 0.932 & & & & \\
& DPPH & 0.717 & 0.414 & & & \\
& ABTS & 0.894 & 0.996 & 0.329 & & \\
& FRAP & 0.869 & 0.629 & 0.968 & 0.556 & \\
& CUPRAC & 0.841 & 0.587 & 0.98 & 0.51 & $0.999^{*}$ \\
\hline \multirow{5}{*}{ Freeze-dried } & TFC & 0.979 & & & & \\
& DPPH & -0.012 & 0.19 & & & \\
& ABTS & 0.922 & 0.825 & -0.398 & & \\
& FRAP & 0.859 & 0.945 & 0.502 & 0.594 & \\
& CUPRAC & 0.914 & 0.977 & 0.395 & 0.685 & 0.993 \\
\hline \multirow{5}{*}{ Fresh } & TFC & -0.909 & & & & \\
& DPPH & 0.914 & -0.661 & & & \\
& ABTS & -0.253 & -0.173 & -0.624 & & \\
& FRAP & 0.974 & -0.79 & 0.982 & -0.467 & \\
& CUPRAC & 0.507 & -0.102 & 0.814 & -0.962 & 0.69 \\
\hline
\end{tabular}

$\mathrm{X}$ Total phenolic content (TPC), total flavonoid content (TFC), radical-scavenging activity (DPPH), radical-scavenging activity (ABTS), ferric-reducing antioxidant power

(FRAP) and cupric reducing antioxidant capacity (CUPRAC), ${ }^{\mathrm{y}}$ Replication, $*$ Significant level at $\mathrm{p}<0.05$.

activities of fresh fig leaves showed negative correlations except for TPC with DPPH (0.914), FRAP (0.974) and CUPRAC (0.507), DPPH with FRAP (0.982) and CUPRAC (0.814) and FRAP with CUPRAC (0.690). Negative correlations were shown between TPC with TFC (-0.909) and ABTS with CUPRAC (-0.962).

\subsection{Principal component analysis (PCA)}

The PCA of fig leaves achieved by various drying process is shown in Figure 1. Fig leaves' cultivars showed the same trend. For fig cultivar BTM 6 leaves, the PC1 vs. PC2 biplot accounted for $99.21 \%$ of the total variance $(\mathrm{PC} 1=97.46 \%, \mathrm{PC} 2=1.75 \%)$. According to Figure 1 (A), fresh leaves grouped on the left of the graph, freeze dried and oven dried leaves at $50^{\circ} \mathrm{C}$ and $60^{\circ} \mathrm{C}$ were grouped in the middle of the graph. While oven drying at $40^{\circ} \mathrm{C}$ clustered on the right side of this figure. This distribution revealed that different drying processes present significant differences $(p<0.05)$ in the antioxidant, TPC and TFC activities. Oven drying at $40^{\circ} \mathrm{C}$ grouped together with antioxidant, TPC and TFC assays. Based on grouping, TPC and ABTS were formed into one group, similarly, with TFC, DPPH and FRAP, while CUPRAC stands alone. As for fig cultivar TGF-J leaves, the PC1 vs PC2 biplot accounted for $94.75 \%$ of total variance $(\mathrm{PC} 1=94.74 \%, \mathrm{PC} 2=3.99 \%)$ (Figure 1 (B)) and for fig cultivar MD-J leaves, the PC1 vs. PC2 biplot accounted for $97.09 \%$ of total variance $(\mathrm{PC} 1=$ $97.09 \%$, PC2 $=2.01 \%)($ Figure $1(\mathrm{C})$ ).

\section{Discussion}

The stabilization of plant leaves by drying comprises fluctuation in the plant matter which could alter the combinations of chemical structure in the dry matter and the extractability (Mediani et al., 2014; Pham et al., 2015). Hence, in this study the antioxidant, TPC and TFC activities of fig leaves dried with various drying processes were assessed. Higher oven drying temperature showed reduction in the activities. Moreover, the reduction of antioxidant levels in the fig leaves correlated with the TPC and TFC activities (Table 2 ), an indication that the reduction of antioxidant activities in fig leaves with oven drying at $50^{\circ} \mathrm{C}$ and 

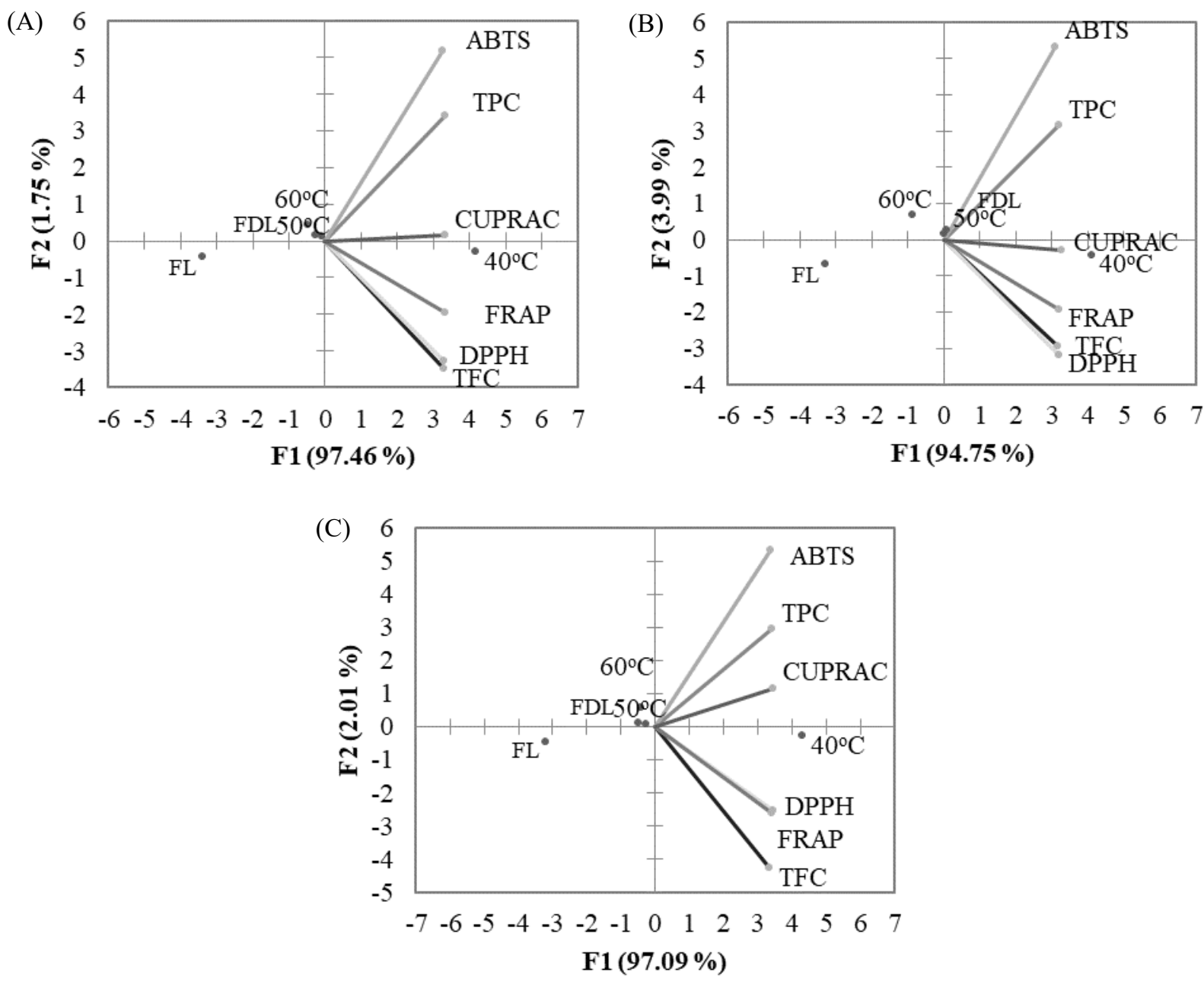

Figure 1. Principal component analysis on the effect of drying process of three fig (Ficus carica L.) leave cultivars (A) Brown Turkey Masuri 6 (BTM 6), (B) Masui Dauphine Jumbo (MD-J) and (C) Taiwan Golden Fish Jumbo (TGF-J) based on antioxidant activities (DPPH, ABTS, FRAP and CUPRAC), total phenolic (TPC) and total flavonoid (TFC) contents

FL: Fresh leaves; FDL: freeze dried leaves. F1 = Factor 1; F2 = Factor 2

above are due to deterioration of the phenolic and flavonoid compounds. Consequently, drying process is crucial in the production of fig leaves which preserve their antioxidant activities and levels of polyphenolic compounds. Larrauri et al. (1998) suggested that thermal degradation was the main reason of significant decline of antioxidant activity with drying at high temperatures up to $100^{\circ} \mathrm{C}$, which agrees with the current findings. Katsube et al. (2003) for the purpose of drying of mulberry leaves, temperatures between $40-110^{\circ} \mathrm{C}$ were used. Wiriya et al. (2009) dried chilies at temperatures between $50-70^{\circ} \mathrm{C}$ and Rodríguez et al. (2016) dried Aristotelia berries at $40-80^{\circ} \mathrm{C}$. According to the abovementioned references, when drying temperatures used lower than $60^{\circ} \mathrm{C}$, this involves a lengthier drying period especially with air drying, causing a reduction in phenolic content in the presence of oxygen which causes oxidation. While using temperatures at $60^{\circ} \mathrm{C}$ and above lower the phenolic content because of thermal degradation. Comparing other researchers' results with the current findings using lower temperature at $40^{\circ} \mathrm{C}$ for $48 \mathrm{hrs}$ in the oven confirmed that the drying method and temperature is chosen were crucial and should be studied for each plant types and parts.

It suggests that the drying process affects the antioxidant activities, TPC and TFC. Thermal drying at $40^{\circ} \mathrm{C}$ showed the highest correlation among TPC, TFC and antioxidant activities, while thermal drying at $50^{\circ} \mathrm{C}$ showed the least positive or negative correlations. Thermal drying at $60^{\circ} \mathrm{C}$ and freeze drying showed a similar trend, while fresh fig leaves showed mostly negative correlations especially between TPC and TFC.

The strong negative relationship proposed that different drying processes might affect the behaviour of the antioxidant activities, TPC and TPC. The negative correlation found between ABTS and DPPH has been reported previously, revealing that some of the secondary metabolites with ABTS activity may not show radical scavenging capacity by DPPH assay (Wang et al., 1998; Thoo et al., 2010).

\section{Conclusion}

It was found that oven drying at $40^{\circ} \mathrm{C}$ showed the highest antioxidant activities, TPC and TFC. In order to 
improve the drying processes, the temperature of drying has to be as low as possible without reducing the fig product quality.

\section{Acknowledgment}

The authors appreciate the funding contribution from the Ministry of Education (FRGS/1/2014/STWN03/ UKM/02/1 and FRGS/1/2017/WAB01/UKM/02/4) and the Universiti Kebangsaan Malaysia (DIP-2014-007).

\section{References}

Abdullah Sani, N., Sawei, J., Ratnam, W. and Rahman, Z.A. (2018). Physical, antioxidant and antibacterial properties of rice (Oryza sativa L.) and glutinous rice (Oryza sativa var. glutinosa) from local cultivators and markets of Peninsular, Malaysia. International Food Research Journal, 25(6), 2328-2336.

Ahmad, J., Khan, S. and Iqbal, D. (2013). Evaluation of antioxidant and antimicrobial activity of Ficus carica leaves an in vitro approach. Journal of Plant Pathology and Microbiology, 4(1), 1-4.

Allahyari, S., Delazar, A. and Najafi, M. (2014). Evaluation of general toxicity, anti-oxidant activity and effects of Ficus carica leaves extract on ischemia/reperfusion injuries in isolated heart of rat. Advanced Pharmaceutical Bulletin, 4(Suppl. 2), 577582.

Aminah, A. and Permatasari, K.A. (2013). Effect of drying and cooking methods on antioxidant properties of bitter gourd (Momordica charantia). Journal of Tropical Agriculture and Food Science, 41(2), 249-256.

Apak, R., Güclü, K., Özyürek, M. and Celik, S.E. (2008). Mechanism of antioxidant capacity assays and the CUPRAC (cupric ion reducing antioxidant capacity) assay. Microchimica Acta, 160(4), 413419. https://doi.org/10.1007/s00604-007-0777-0

Asami, D.K., Hong, Y.J., Barrett, D.M. and Mitchell, A. E. (2003). Comparison of the total phenolic and ascorbic acid content of freeze dried and air-dried marionberry, strawberry, and corn grown using conventional, organic, and sustainable agricultural practices. Journal of Agricultural and Food Chemistry, 51(5), 1237-1241. https:// doi.org/10.1021/jf020635c

Association of Social Analytical Chemist (AOAC). (1990). Official methods of analysis. Arlington, USA: AOAC.

Bakar, M.F.A., Mohamed, M., Rahmat, A. and Fry, J. (2009). Phytochemicals and antioxidant activity of different parts of bambangan (Mangifera pajang) and tarap (Artocarpus Odoratissimus). Food
Chemistry 113(2), 479-483. https://doi.org/10.1016/ j.foodchem.2008.07.081

Benzie, I.F. and Strain, J. (1999). Ferric reducing/ antioxidant power assay: direct measure of total antioxidant activity of biological fluids and modified version for simultaneous measurement of total antioxidant power and ascorbic acid concentration. Methods in Enzymology, 299, 15-27. https:// doi.org/10.1016/S0076-6879(99)99005-5

Benzie, I.F. and Strain, J.J. (1996). The ferric reducing ability of plasma (FRAP) as a measure of "Antioxidant Power": The FRAP assay. Analytical Biochemistry, 239(1), 70-76. https://doi.org/10.1006/ abio.1996.0292

Calixto, J. (2000). Efficacy, safety, quality control, marketing and regulatory guidelines for herbal medicines (phytotherapeutic agents). Brazilian Journal of Medical and Biological Research, 33(2), 179-189. https://doi.org/10.1590/S0100879X2000000200004

Chan, E.W. C., Lim, Y.Y., Wong, S.K., Lim, K., Tan, S., Lianto, F. and Yong, M. (2009). Effects of different drying methods on the antioxidant properties of leaves and tea of ginger species. Food Chemistry, 113(1), 166-172. https://doi.org/10.1016/ j.foodchem.2008.07.090

Chang, C.H., Lin, H.Y., Chang, C.Y. and Liu, Y.C. (2006). Comparisons on the antioxidant properties of fresh, freeze dried and hot-air-dried tomatoes. Journal of Food Engineering, 77(3), 478-485. https://doi.org/10.1016/j.jfoodeng.2005.06.061

Hossain, M., Barry-Ryan, C., Martin-Diana, A.B. and Brunton, N. (2010). Effect of drying method on the antioxidant capacity of six Lamiaceae herbs. Food Chemistry, 123(1), 85-91. https://doi.org/10.1016/ j.foodchem.2010.04.003

Katsube, T., Yamasaki, Y., Iwamoto, M. and Oka, S. (2003). Hyaluronidase-inhibiting polysaccharide isolated and purified from hot water extract of sporophyll of Undaria pinnatifida. Food Science and Technology Research, 9(1), 25-29. https:// doi.org/10.3136/fstr.9.25

Larrauri, J.A., Sánchez-Moreno, C. and Saura-Calixto, F. (1998). Effect of temperature on the free radical scavenging capacity of extracts from red and white grape pomace peels. Journal of Agricultural and Food Chemistry, 46(7), 2694-2697. https:// doi.org/10.1021/jf980017p

Lim, Y. and Murtijaya, J. (2007). Antioxidant properties of Phyllanthus amarus extracts as affected by different drying methods. LWT-Food Science and 
Technology, 40(9), 1664-1669. https:// doi.org/10.1016/j.lwt.2006.12.013

Mediani, A., Abas, F., Tan, C.P. and Khatib, A. (2014). Effects of different drying methods and storage time on free radical scavenging activity and total phenolic content of Cosmos caudatus. Antioxidants, 3(2), 358370. https://doi.org/10.3390/antiox3020358

Musa, K. H., Abdullah, A., Jusoh, K. and Subramaniam, V. (2011). Antioxidant activity of pink-flesh guava (Psidium guajava L.): effect of extraction techniques and solvents. Food Analytical Methods, 4(1), 100107. https://doi.org/10.1007/s12161-010-9139-3

Oliveira, W.P., Bott, R.F. and Souza, C.R. (2006). Manufacture of standardized dried extracts from medicinal Brazilian plants. Drying Technology, 24 (4), 523-533. https:// doi.org/10.1080/07373930600612073

Panche, A.N., Diwan, A.D. and Chandra, S.R. (2016). Flavonoids: an overview. Journal of Nutritional Science, 5, 1-15. https://doi.org/10.1017/jns.2016.41

Pham, H., Nguyen, V., Vuong, Q., Bowyer, M. and Scarlett, C. (2015). Effect of extraction solvents and drying methods on the physicochemical and antioxidant properties of Helicteres hirsuta Lour. Leaves. Technologies, 3(4), 285-301. https:// doi.org/10.3390/technologies3040285

Rodríguez, K., Ah-Hen, K.S., Vega-Gálvez, A., Vásquez, V., Quispe-Fuentes, I., Rojas, P. and Lemus-Mondaca, R. (2016). Changes in bioactive components and antioxidant capacity of maqui, Aristotelia chilensis [Mol] Stuntz, berries during drying. LWT-Food Science and Technology, 65, 537542. https://doi.org/10.1016/j.lwt.2015.08.050

Roy, M.K., Takenaka, M., Isobe, S. and Tsushida, T. (2007). Antioxidant potential, anti-proliferative activities, and phenolic content in water-soluble fractions of some commonly consumed vegetables: Effects of thermal treatment. Food Chemistry, 103 (1), 106-114. https://doi.org/10.1016/ j.foodchem.2006.08.002

Sagrin, M.S. and Chong, G. (2013). Effects of drying temperature on the chemical and physical properties of Musa acuminata Colla (AAA Group) leaves. Industrial Crops and Products, 45, 430-434. https:// doi.org/10.1016/j.indcrop.2012.12.036

Shahinuzzaman, M., Yaakob, Z., Abdullah Sani, N., Akhtar, P., Islam, M. Z., Mimi, M.A. and Shamsudin, S. A. (2019). Optimization of extraction parameters for antioxidant and total phenolic content of ficus carica L. Latex from white genoa cultivar. Asian Journal of Chemistry, 31(8), 1859-1865.
Singleton, V.L. and Rossi, J.A. (1965). Colorimetry of total phenolics with phosphomolybdicphosphotungstic acid reagents. American Journal of Enology and Viticulture 16(3), 144-158.

Tan, B.L., Norhaizan, M.E., Liew, W.P.P. and Rahman, H.S. (2018). Antioxidant and oxidative stress: A mutual interplay in age-related diseases. Frontiers in Pharmacology, 9(1162), 1-28. https:// doi.org/10.3389/fphar.2018.01162

Tan, E.S., Abdullah, A. and Maskat, M.Y. (2013). Effect of drying methods on total antioxidant capacity of bitter gourd (Momordica charantia) fruit. AIP Conference Proceedings, 1571, 710-716. https:// doi.org/10.1063/1.4858738

Thoo, Y.Y., Ho, S.K., Liang, J.Y., Ho, C.W. and Tan, C.P. (2010). Effects of binary solvent extraction system, extraction time and extraction temperature on phenolic antioxidants and antioxidant capacity from mengkudu (Morinda citrifolia). Food Chemistry, 120(1), 290-295. https://doi.org/10.1016/ j.foodchem.2009.09.064

Trifunschi, S.I. and Dorina G.A. (2013). Flavonoid extraction from Ficus carica leaves using different techniques and solvents. Zbornik Matice Srpske Za Prirodne Nauke, 2013(125), 81-86. https:// doi.org/10.2298/ZMSPN1325081T

Van den Berg, R., Haenen, G.R., van den Berg, H. and Bast, A. (1999). Applicability of an improved Trolox equivalent antioxidant capacity (TEAC) assay for evaluation of antioxidant capacity measurements of mixtures. Food Chemistry, 66(4), 511-517. https:// doi.org/10.1016/S0308-8146(99)00089-8

Wang, M., Li, J., Rangarajan, M., Shao, Y., LaVoie, E.J., Huang, T.C. and Ho, C.T. (1998). Antioxidative phenolic compounds from sage (Salvia officinalis). Journal of Agricultural and Food Chemistry, 46(12), 4869-4873. https://doi.org/10.1021/jf980614b

Wiriya, P., Paiboon, T. and Somchart, S. (2009). Effect of drying air temperature and chemical pretreatments on quality of dried chilli. International Food Research Journal, 16(3), 441-454. 